\title{
European trade associations move to consolidate
}

OXFORD, U.K.-As a result of the recent formation of the Biotechnology Industry Organization (BIO, Washington, DC), the U.S. biotech industry is now able to present a unified face to the world. In Europe, the situation appears to be moving in the same direction, but by a different route. Instead of merging existing trade associations, as BIO did, a new industrial organization has emerged in Europe, drawing upon the experience of the major pan-European industry-sector federations, including those representing chemical manufacturers, food manufacturers, plant breeders, diagnostic producers, and animal-health-product makers. These federations have established the Forum for European BioIndustry Coordination (FEBC, Brussels, Belgium) to provide a single gateway through which European Community (EC) institutions can discuss biotechnology-related issues with European industry.

"The main message of FEBC is that there is no such thing as a biotechnology industry, but that biotechnology is a set of tools that are being used in a range of industries," explains Brian Ager of the Senior Advisory Group on Biotechnology (SAGB, Brussels, Belgium). SAGB - a trade association representing both large and small companies, across all industry sectors, that use biotechnology - will provide the secretariat for FEBC.

\section{Europe}

FEBC, however, has decided that there is no place at its table for the European Secretariat of National Biotechnology Associations (ESNBA, Brussels, Belgium), an organization established by the $\mathrm{Na}$ tional Bioindustry Associations (NBAs) to gain access to the EC. Indeed, some prominent ESNBA members are concerned that FEBC will usurp its position.

But Ager does not want a tradeassociation war. "While the NBAs do a good job at the national level, the ESNBA is a heterogeneous grouping and does not have representation from all member states," says Ager. Another possible reason why FEBC is avoiding ESNBA is that some of FEBC's founding federations blame the NBAs for the demise of the European Biotechnology Coordinating Group(EBCG, Brussels, Belgium). Like FEBC, EBCG started off with the major sector federations, but soon such groups as the NBAs joined and, according to one observer, EBCG became too unwieldy and ended up no more than a talking shop.

There is also concern that ESNBA does not represent the major biotech players, although the reverse argument is being used against FEBC, that it only represents the voice of big business. While it is true that the founding federations of FEBC are mainly made up of large companies, there are some small-sized to medium-sized firms in their roll calls. Yet the NBAs that make up ESNBA contain just small-sized to medium-sized companies.

\section{U.K.}

But if the situation at the panEuropean level looks confused, in the U.K. it is just short of chaotic. Through informal discussions, officials at the U.K. Department of Trade \& Industry (DTI) have signaled to British industry that they would like to deal with one grouping when it comes to biotechnology, so that the views it hears are consistent. At the moment, DTI finds that it has to consult with, among others, all the sector trade associations, the Confederation of British Industry's (CBI, London) biotechnology working party, the BioIndustry Association (BIA, London), and individual companies.

Yet it is not clear if one true voice will emerge. DTI is not making the job easy, as it refuses to suggest the criteria that would fulfill a one-stop shop, because it does not want to be prescriptive. Ron Coleman, BIA's president, is looking at the issue of who is best placed to broadcast the biotech industry's views. But those who have seen drafts of Coleman's position paper say that he is proposing that BIA play the leading role. The idea that BIA should carry the gauntlet for all of U.K. biotechnology is not a view that will find general acclaim, however. Alternative options include using the CBI biotechnology working party as the main focus, beefing up DTI's own
Biotechnology Industry/Government Regulatory Advisory Group (BIGRAG), or establishing a brand new grouping that would mirror FEBC at a national level.

While BIA does boast a membership of more than 150 companies, including most of the U.K.'s startups, its critics claim that it does not truly represent the major industrial users of biotechnology, as Unilever (Rotterdam, The Netherlands) is BIA's only large industrial member. These critics contend that "service industry" companies-like law firms, management consultants, and even publishers - have too much influence in BIA policy decisions.

Simon Shohet, secretary of the CBI biotechnology working party, believes that DTI's request makes sense, but he adds that discussions about who best represents the interests of biotechnology have been taking place for more than ten years without any real conclusion. "Any organization claiming to represent biotechnology users must first have a good cross section of members, including most of the major players. It must also have links with the EC and to some extent with the U.S. and Japan," says Shohet.

Jeff Kipling of the Association of the British Pharmaceutical Industry believes that both the CBI biotechnology working party and DTI's BIGRAG offer a good option for biotech representation. "DTI's BIGRAG contains both relevant government agencies and representatives of the major industrial groupings. The CBI group contains all the trade associations, including BIA, as well as individual expert industrialists from companies such as Glaxo, Unilever, and Zeneca Seeds," says Kipling.

But while most of the stakeholders agree that there is a need for consolidation among those claiming to represent biotechnology interests, it is clear that each trade association is driven by what its members want. While at the European level, FEBC may provide legislators with their one-stop option, in the U.K., it is still too early to determine how DTI's request will be met. -Mike Ward Mike Ward is a freelance journalist in Oxford, U.K.
While there's

clearly a need for

consolidation

among biotech

trade

associations, each association

is driven by what

its members

want. 